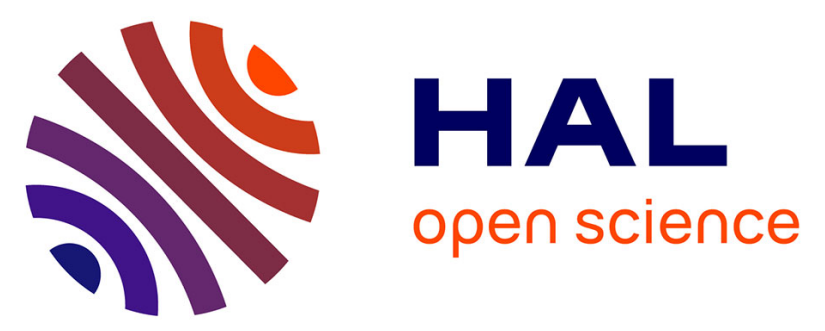

\title{
Malleable Electronic Structure of Chloranilic Acid and Its Species Determined by X-ray Charge Density Studies
}

Vedran Vuković, Krešimir Molčanov, Christian Jelsch, Emmanuel Wenger, Anna Krawczuk, Marijana Jurić, Lidija Androš Dubraja, Biserka Kojić-Prodić

\section{- To cite this version:}

Vedran Vuković, Krešimir Molčanov, Christian Jelsch, Emmanuel Wenger, Anna Krawczuk, et al.. Malleable Electronic Structure of Chloranilic Acid and Its Species Determined by X-ray Charge Density Studies. Crystal Growth \& Design, 2019, 19 (5), pp.2802-2810. 10.1021/acs.cgd.9b00033 . hal02123911

\section{HAL Id: hal-02123911 \\ https://hal.science/hal-02123911}

Submitted on 9 May 2019

HAL is a multi-disciplinary open access archive for the deposit and dissemination of scientific research documents, whether they are published or not. The documents may come from teaching and research institutions in France or abroad, or from public or private research centers.
L'archive ouverte pluridisciplinaire HAL, est destinée au dépôt et à la diffusion de documents scientifiques de niveau recherche, publiés ou non, émanant des établissements d'enseignement et de recherche français ou étrangers, des laboratoires publics ou privés. 


\section{Malleable electronic structure of chloranilic acid and its species determined by X-ray charge density studies}

Publication Date (Web): April 9, 2019. Cryst. Growth Des., 2019, 19 (5), pp 2802-2810 DOI: 10.1021/acs.cgd.9b00033

Vedran Vuković, ${ }^{1,2}$ Krešimir Molčanov, ${ }^{1 *}$ Christian Jelsch, ${ }^{2 *}$ Emmanuel Wenger, ${ }^{2}$ Anna Krawczuk, ${ }^{3}$ Marijana Jurić, ${ }^{1}$ Lidija Androš Dubrajal ${ }^{1}$ and Biserka Kojić-Prodićl ${ }^{1}$

${ }^{1}$ Rudjer Bošković Institute, Bijenička 54, Zagreb HR-10000, Croatia

${ }^{2} \mathrm{CRM}^{2}$ CNRS, UMR 7036, Institut Jean Barriol, Université de Lorraine, BP 70239, Vandoeuvre-lès-Nancy, France

${ }^{3}$ Faculty of Chemistry, Jagiellonian University, Gronostajowa 2, 30-387 Krakow, Poland e-mail: kmolcano@irb.hr; christian.jelsch@univ-lorraine.fr

KEYWORDS chloranilic acid, electron structure, delocalisation, X-ray charge density

\section{SYNOPSIS.}

Electronic structure of five species of chloranilic acid (neutral molecule, mono- and dianion, and two chelating modes - bidendate and (bis)bidentate) is determined by X-ray charge density studies. Electron density at the bond critical points yields an accurate measure of bond order and therefore electron delocalisation. $\pi$-electron system of chloranilic acid is especially malleable, so it can adopt various degrees of delocalisation, depending on ionisation and molecular environment. 


\begin{abstract}
Herein, we present a detailed X-ray charge density study of the electron delocalisation in five species of the chloranilic acid: neutral molecule, mono- and dianion, and two chelating modes - bidendate and (bis)bidentate. The experiments provide the electron density at the bond critical points, which yields an accurate measure of bond order (and therefore electron delocalisation), and complements previous literature and our data on bond lengths extracted from crystal structures and infrared spectra. Mapping of the electrostatic potential indicates electronrich and electron-poor areas in the molecule, corresponding to single (electron-poor), double and delocalised bonds (electron-rich) that can explain stacking interactions of quinoid rings in crystal packing.
\end{abstract}

\title{
INTRODUCTION
}

Motivation for an extensive investigation of the electronic structure of chloranilic acid, 3,6dichloro-2,5-dihydroxy-1,4-quinone $\left(\mathrm{H}_{2} \mathrm{CA}\right)$ as a member of a well-known group of substituted 2,5-dihydroxyquinones ${ }^{[1]}$ has been found in its versatile chemical properties. It was first prepared in 1891 by Graebe. ${ }^{[2]}$ Its OH groups are easily deprotonated due to an inductive effect of the electronegative chlorine substituents stabilising the anion. Chloranilic acid is therefore an acid of moderate strength with $\mathrm{p} K_{\mathrm{a}}$ values of 0.73 and $3.08 .^{[3]}$ It is a quinoid compound with very diverse chemical behaviour: it is a good metal ligand, ${ }^{[4,5]}$ proton donor and acceptor ${ }^{[6]}$ and it is prone for strong stacking interactions. ${ }^{[7-9]}$ Versatility of its functions originates from highly malleable $\pi$ electron system, which can adopt various degrees of delocalisation, depending on ionisation and 
molecular environment. The neutral form of chloranilic acid (Scheme 1) is a typical paraquinone, while its dianion form reveals two delocalised 1-oxo-3-hydroxyallyl-like systems joined together in a six-membered ring by two single $\mathrm{C}-\mathrm{C}$ bonds. The mono anion, however, has a delocalised system over one half of the ring, while the other half has distinguishable single and double bonds. It can also bind to metals either as a bridging (bis)bidentate ligand, which has a dianion-like structure or as a terminal bidentate ligand with an ortho-quinoid structure (Scheme $1)$.

Differences in molecular geometry, related to changes of electronic structure, affect significantly infrared (IR) spectra: C-C and C-O stretching bands display a variety of red- and blue-shifts. Like other 2,5-dihydroxyquinones, it is a versatile ligand towards transition metals, ${ }^{[4,5]}$ and behaves similarly to oxalate. ${ }^{[10]}$ A variety of chloranilate complexes are known with topologies ranging from discrete mono- and binuclear units, ${ }^{[10-14]} 1 \mathrm{D}$ linear ${ }^{[15-18]}$ and zig-zag ${ }^{[12,18-23]}$ polymers, $2 \mathrm{D}^{[16,24-27]}$ and 3D networks. ${ }^{[28,29]}$ The most common coordination modes are bridging (bis)bidentate ${ }^{[12,15,30]}$ and terminal bidentate. ${ }^{[10,11]}$ Their topologies affect magnetic exchange interactions. $^{[24,31-33]}$

Chloranilic acid also readily forms salts and co-crystals with alkali ${ }^{[1,7,8]}$ and organic cations involving a proton transfer. ${ }^{[6]}$ These properties of chloranilic acid have been widely used in analytical procedures exemplified by visible spectrophotometric determination of various pharmaceuticals, such as valsartan (blocking the action of angiotensin and dilating blood vessels manifested by reduced blood pressure) $\cdot{ }^{[34]}$ Determination of metals using complexation ability of chloranilic acid in adsorption stripping voltammetry for metal traces has been exploited: detection of uranium traces in nuclear reactor IEA-R1 pool-water ${ }^{[35]}$ and for sensitive quantification $\mathrm{Ge}(\mathrm{IV}) .{ }^{[36]}$ 
Chloranilic acid is a strong donor and acceptor of hydrogen bonds ${ }^{[6,37]}$ and also possesses an unusual propensity for cycle stacking. While chloranilate dianions stack similarly to aromatic rings, ${ }^{[1]}$ hydrogen chloranilate monoanions and neutral molecules are able to form unprecedented face-to-face stacks with very short inter-planar distances $(\sim 3.3 \AA) \cdot{ }^{[7,8]}$ Energy of these close interactions is comparable to medium-strong hydrogen bonds, ${ }^{[9]}$ exhibiting potential for crystal engineering. Similar stacks are observed in analogous compounds such as bromanilic acid ${ }^{[38]}$ and unsubstituted 2,5-dihydroxyquinone. ${ }^{[39]}$

Electronic structure of chloranilic acid, particularly delocalisation of $\pi$ electrons, changes significantly upon (de)protonation and complexation of transition metals (Scheme 1), affecting molecular geometries. ${ }^{[1,6,11]}$ These changes are documented by corresponding IR spectra: neutral molecule ( $p$-quinoid ring $)^{[37,40]}$ and terminal bidentate chloranilate ligand (o-quinone $)^{[10-12,15]}$ have two C-O stretching bands, close to single and double bonds, whereas in dianions and bridging (bis)bidentate chloranilate ligands, only one $\mathrm{C}-\mathrm{O}$ stretch is observed, corresponding to a delocalised bond. ${ }^{[12,15]}$ Recent X-ray charge density studies of potassium hydrogen chloranilate

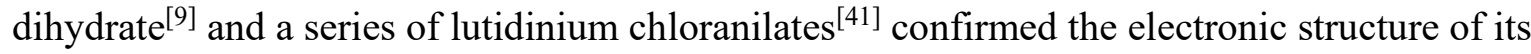
mono-anion and di-anion forms (Scheme 1, forms II and III). Variability of electronic structure of chloranilic acid and its anions prompted us to a detailed X-ray charge density study of its species (Scheme 1). Here, we present structures of neutral and metal chelating species (Scheme 1, forms $\mathbf{I}, \mathbf{I V}, \mathbf{V}$ ) and compare them to mono-anion and dianion species (Scheme 1, forms $\mathbf{I I}^{[9]}$ and III, this work and ref. ${ }^{[41]}$ ).

To minimize problems with X-ray absorption, we carefully selected compounds which readily grow well-developed crystals, comprise atoms as light as possible and have as small asymmetric 
units as possible. To emphasize difference in electron delocalisation, we will use the atom numbering scheme shown in Fig. 1 for all structures discussed.<smiles>O=C1C(O)=C(Cl)C(=O)C(O)=C1Cl</smiles><smiles></smiles>

IV<smiles>[M]OC1=C(Cl)C(=O)C(=O)C(Cl)=C1O</smiles>

V

Scheme 1 The most common species of chloranilic acid (I) and its anions (II and III) capable of forming metal and organic salts and metal complexes (IV and V).

\section{RESULTS AND DISCUSSION}

We have determined X-ray charge densities of the following compounds: chloranilic acid dihydrate (I), potassium chloranilate monohydrate (III), coordination polymer $\left[\mathrm{Mn}(\mathrm{CA})\left(\mathrm{H}_{2} \mathrm{O}\right)\right]_{n}$ $(\mathbf{I V})^{[18]}$ and a mononuclear complex $\left[\mathrm{Cu}(\mathrm{CA})_{2}\left(\mathrm{H}_{2} \mathrm{O}\right)_{2}\right] \mathrm{Him}_{2}(\mathbf{V}, \mathrm{Him}=$ imidazolium $) .{ }^{[15]}$ In addition, we also consider previously published potassium hydrogen chloranilate dihydrate 
(II). ${ }^{[9]}$ To facilitate comparison, we use the atom numbering scheme shown in Fig. 1 for all structures; in the case of centrosymmetric rings (in I, III and V), the adequate symmetry equivalence is indicated.

Bond orders and main parameters of electron density topology in the chloranilate moieties are given in Fig. 2 and Tables 1 and 2; more details can be found in the Supporting Information, Tables S1-S5 and Figs. S16-S17. As can be seen from Fig. 2, our results confirm previously established structures (Scheme 1). Geometries of hydrogen chloranilate monoanion and chloranilate dianion (II and III) $)^{[1,6,7]}$ are consistent with Fig. 2 and Table 2. Geometries of the coordinated species $\mathbf{I V}$ and $\mathbf{V}^{[10-12,15]}$ are also in agreement with Fig. 2 and Tables 2.

Atomic charges (Table 3; more details, including Bader charges are in the Supporting information, Tables S6-S13) nicely illustrate stabilisation of the anions by electron delocalisation. After deprotonation, both oxygen atoms in the delocalised fragments O1-C1-C6$\mathrm{C} 5-\mathrm{O} 4$ and $\mathrm{O} 2-\mathrm{C} 2-\mathrm{C} 3-\mathrm{C} 4-\mathrm{O} 3$ have a partial negative charge between -0.25 and $-0.30 \mathrm{e}$. Inductive effect of the chlorine atoms is responsible for further stabilisation: their charge increases from -0.11 in the neutral $\mathrm{H}_{2} \mathrm{CA}$ to -0.36 e in $\mathrm{CA}^{2-}$ (Table 3). Thus, the effect of chlorine substitution is similar to the one observed in tetrachlorosemiquinone radical anions. ${ }^{[2,43]}$ In the coordinated species IV and $\mathbf{V}$, there is no such effect and more negative charge is located at the coordinating oxygen atoms, probably due to donation of electron density to the $d$ orbitals of the metal cations. Accordingly, electron density and the corresponding bond orders of C-O bonds are significantly lower than in the non-coordinated species (Table 2).

According to the topology of electron density (Table 4), metal-oxygen bonds can be characterised as intermediate cases between strongly polar and ionic. ${ }^{[44-48]} \mathrm{Mn}-\mathrm{O}$ bonds have 
significantly lower electron density $\left(0.24-0.29\right.$ e $\left.\AA^{-3}\right)$ than $\mathrm{Cu}-\mathrm{O}$ (equatorial bonds: $0.36-0.42 \mathrm{e}$ $\AA^{-3}$ ), indicating more pronounced ionic character, as has been previously observed in different complexes. ${ }^{[44-46]}$ The apical $\mathrm{Cu}-\mathrm{O}$ bond is elongated, and its maximum electron density is only 0.14 e $\AA^{-3}$; thus it can be regarded as predominantly ionic.
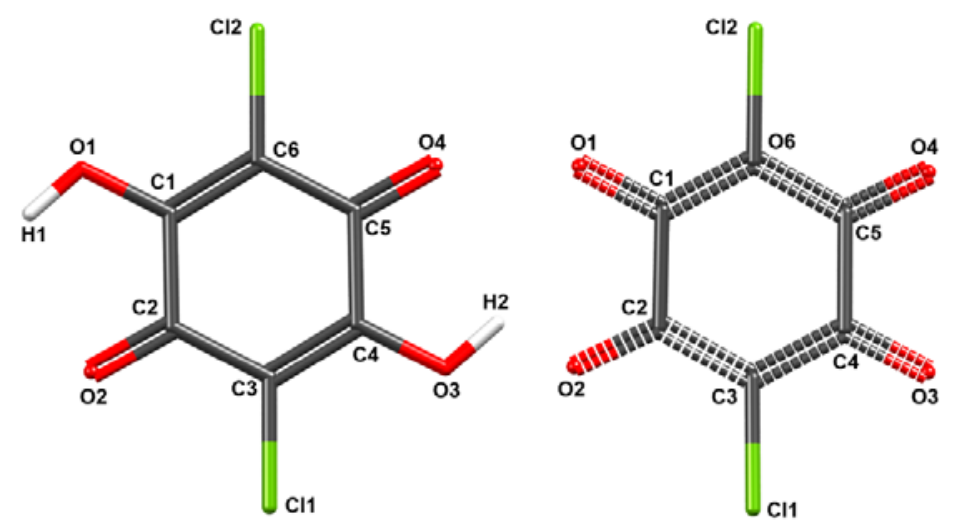

Figure 1 Atom numbering scheme used for the structures discussed. Bonds with delocalised $\pi$ electrons are represented as dashed double lines. Labelling on the left is used for compounds I and II and the right one for compounds III, IV and V. 


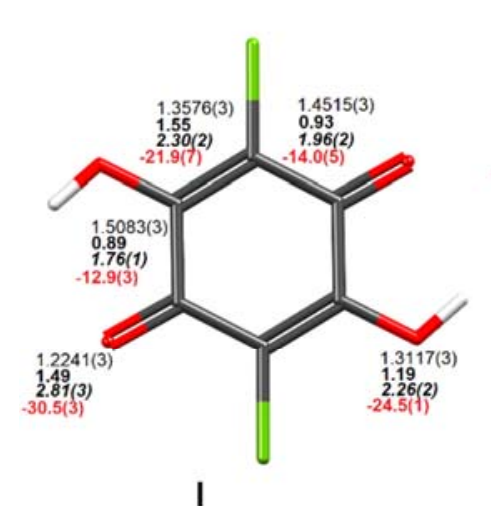

I

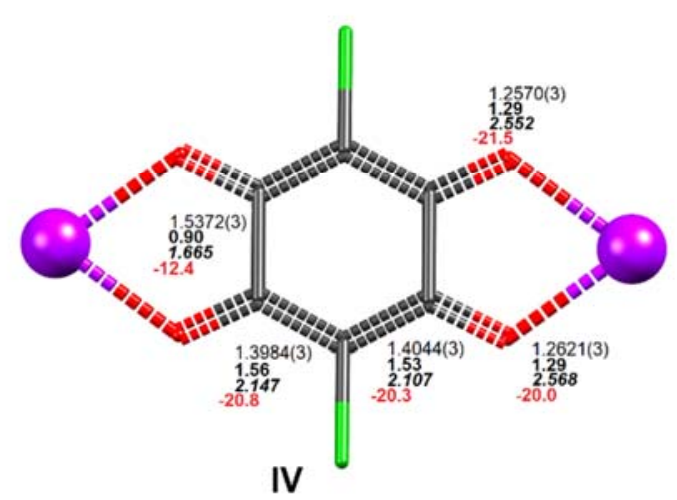

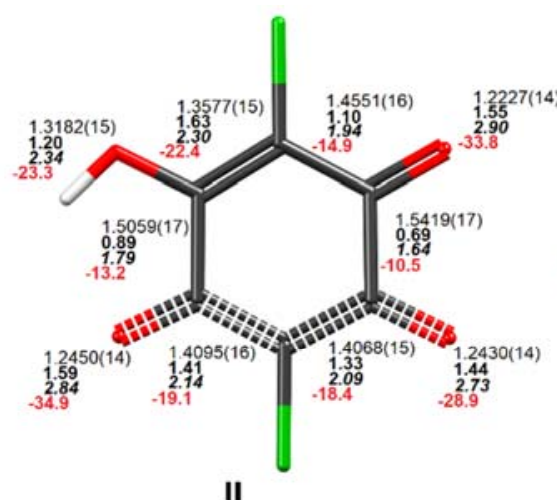

II

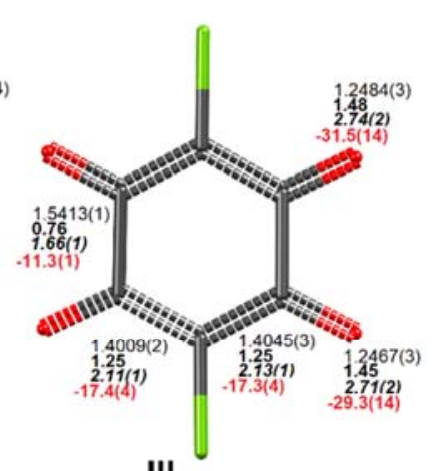

III

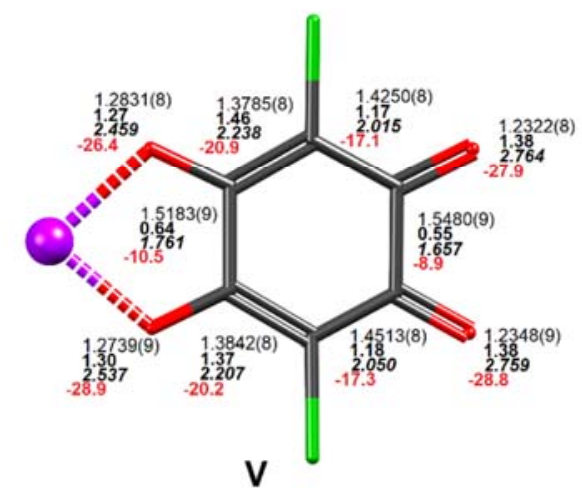

Figure 2 Structures studied among the five most common species of chloranilic acid and its anions with bonding parameters indicated: bond length (first entry), bond order (second entry, bold), $\rho_{\mathrm{cp}}$ electron density at the critical point (third entry, italic), Laplacian (fourth entry, red). 
Table 1 Bond lengths in the five most common form of chloranilic acid. Bonds C4-C5, C5-C6, C6-C1, C4-O3 and C5-O4 are symmetry equivalents of bonds $\mathrm{C} 1-\mathrm{C} 2, \mathrm{C} 2-\mathrm{C} 3, \mathrm{C} 3-\mathrm{C} 4, \mathrm{C} 1-\mathrm{O} 1$ and C2-O2, respectively, in compounds I, III and IV, obtained with the following symmetry operators: i) $x,-y,-z$; ii) $-x,-y,-z$; iii) $1 / 2-x,{ }^{3} / 2-y, 1-z$.

\begin{tabular}{llllll}
\hline & I & II & III & IV & V \\
\hline C1-C2 & $1.5083(3)$ & $1.5059(17)$ & $1.5413(1)$ & $1.5372(3)$ & $1.5183(9)$ \\
C2-C3 & $1.4515(3)$ & $1.4551(16)$ & $1.4009(2)$ & $1.3984(3)$ & $1.3842(8)$ \\
C3-C4 & $1.3576(3)$ & $1.3577(15)$ & $1.4045(3)$ & $1.4044(3)$ & $1.4153(8)$ \\
C4-C5 & $1.5083(3)^{i}$ & $1.5419(17)$ & $1.5413(1)^{i i}$ & $1.5372(3)^{i i i}$ & $1.5480(9)$ \\
C5-C6 & $1.4515(3)^{i}$ & $1.4068(15)$ & $1.4009(2)^{i i}$ & $1.3984(3)^{i i i}$ & $1.4250(8)$ \\
C6-C1 & $1.3576(3)^{i}$ & $1.4095(16)$ & $1.4045(3)^{i i}$ & $1.4033(3)^{i i i}$ & $1.3785(8)$ \\
C1-O1 & $1.3117(3)$ & $1.3182(15)$ & $1.2467(3)$ & $1.2570(3)$ & $1.2831(8)$ \\
C2-O2 & $1.2241(3)$ & $1.2450(14)$ & $1.2484(3)$ & $1.2621(3)$ & $1.2739(9)$ \\
C4-O3 & $1.3117(3)^{i}$ & $1.2430(14)$ & $1.2467(3)^{i i}$ & $1.2570(3)^{i i i}$ & $1.2342(8)$ \\
C5-O4 & $1.2241(3)^{i}$ & $1.2227(14)$ & $1.2484(3)^{i i}$ & $1.2621(3)^{i i i}$ & $1.2322(8)$ \\
\hline
\end{tabular}


Table 2 Experimentally derived bond orders in the five species of chloranilic acid. More details on topology of electron density are given in the Fig. 2 and Tables S1-S5 in the Supporting Information. When the atoms are symmetry related, the operators are shown: i) $x,-y,-z$; ii) $-x,-$ $y,-z$; iii) $1 / 2-x,{ }^{3} / 2-y, 1-z$.

\begin{tabular}{llllll}
\hline & I & II & III & IV & V \\
\hline C1-C2 & 0.89 & 0.69 & 0.76 & 0.90 & 0.64 \\
C2-C3 & 1.55 & 1.33 & 1.25 & 1.56 & 1.37 \\
C3-C4 & 0.94 & 1.41 & 1.25 & 1.53 & 1.18 \\
C4-C5 & $0.89^{i}$ & 0.89 & $0.76^{i i}$ & $0.90^{i i i}$ & 0.55 \\
C5-C6 & $1.55^{i}$ & 1.63 & $1.25^{i i}$ & $1.56^{i i i}$ & 1.17 \\
C6-C1 & $0.94^{i}$ & 1.10 & $1.25^{i i}$ & $1.53^{i i i}$ & 1.46 \\
C1-O1 & 1.49 & 1.55 & 1.45 & 1.29 & 1.27 \\
C2-O2 & 1.19 & 1.44 & 1.48 & 1.29 & 1.30 \\
C4-O3 & $1.49^{i}$ & 1.59 & $1.45^{i i}$ & $1.29^{i i i}$ & 1.38 \\
C5-O4 & $1.19^{i}$ & 1.20 & $1.48^{i i}$ & $1.29^{i i i}$ & 1.38 \\
\hline
\end{tabular}


Table 3 Atomic charges in the five forms of chloranilic acid derived from refined population of valence shell $\left(P_{\text {val }}\right)$ values. Atoms $\mathrm{C} 4, \mathrm{C} 5, \mathrm{C} 6, \mathrm{O} 3, \mathrm{O} 4, \mathrm{H} 2$ and $\mathrm{Cl} 2$ are symmetry equivalents of atoms C1, C2, C3, O1, O2, H1 and C11, respectively, in compounds I, III and IV, obtained with the following symmetry operators: $i) x,-y,-z$; ii) $-x,-y,-z$; iii) $1 / 2-x, 3 / 2-y, 1-z$. More details are given in Supporting Information, Tables S6-S13.

\begin{tabular}{llllll}
\hline & I & II & III & IV & V \\
\hline $\mathrm{C} 1$ & $0.00(8)$ & $+0.07(7)$ & $-0.03(3)$ & $+0.06(5)$ & $+0.22(5)$ \\
$\mathrm{C} 2$ & $-0.04(5)$ & $-0.10(9)$ & $-0.03(3)$ & $+0.06(8)$ & $+0.22(8)$ \\
$\mathrm{C} 3$ & $+0.13(7)$ & $-0.23(7)$ & $+0.05(5)$ & $+0.10(7)$ & $-0.33(7)$ \\
$\mathrm{C} 4$ & $0.00(8)^{i}$ & $+0.16(7)$ & $-0.03(3)^{i i}$ & $+0.06(5)^{i i i}$ & $+0.23(5)$ \\
$\mathrm{C} 5$ & $-0.04(5)^{i}$ & $-0.01(8)$ & $-0.03(3)^{i i}$ & $+0.06(8)^{i i i}$ & $+0.23(8)$ \\
$\mathrm{C} 6$ & $+0.13(7)^{i}$ & $-0.13(7)$ & $+0.05(5)^{i i}$ & $+0.10(7)^{i i i}$ & $-0.28(7)$ \\
$\mathrm{O} 1$ & $-0.20(3)$ & $-0.27(6)$ & $-0.28(2)$ & $-0.17(3)$ & $-0.43(3)$ \\
$\mathrm{O} 2$ & $-0.06(3)$ & $-0.17(5)$ & $-0.28(2)$ & $-0.265(3)$ & $-0.42(3)$ \\
$\mathrm{O} 3$ & $-0.20(3)^{i}$ & $-0.33(4)$ & $-0.28(2)^{i i}$ & $-0.17(3)^{i i i}$ & $-0.35(3)$ \\
$\mathrm{O} 4$ & $-0.06(3)^{i}$ & $-0.14(4)$ & $-0.28(2)^{i i}$ & $-0.265(3)^{i i i}$ & $-0.34(3)$ \\
$\mathrm{H} 1$ & $+0.23(3)$ & $+0.33(6)$ & - & - & - \\
$\mathrm{H} 2$ & $+0.23(3)^{i}$ & - & - & - & - \\
$\mathrm{C} 11$ & $-0.11(3)$ & $-0.09(3)$ & $-0.36(3)$ & $-0.06(3)$ & $-0.08(3)$ \\
$\mathrm{C} 12$ & $-0.11(3)^{i}$ & $-0.22(3)$ & $-0.36(3)^{i i}$ & $-0.06(3)^{i i i}$ & $-0.08(3)$ \\
\hline & & & & & \\
\hline & & & & \\
\hline
\end{tabular}


Table 4 Topology of bonds in the metal coordination spheres derived from experimental and theoretical (periodic calculations by CRYSTAL17) electron density after multipole refinement. Symmetry operators: i) $-x, y, 1 / 2-z$; ii) $1 / 2-x, 3 / 2-y, 1-z$.

\begin{tabular}{|c|c|c|c|c|c|c|c|}
\hline & \multirow{2}{*}{$\begin{array}{l}\text { Length } \\
(\AA) \\
\text { exp }\end{array}$} & \multicolumn{2}{|c|}{$\begin{array}{l}\text { Electron Density } \\
\rho_{\mathrm{cp}}\left(\mathrm{e} \AA^{-3}\right)\end{array}$} & \multicolumn{2}{|c|}{$\begin{array}{l}\text { Laplacian } \\
\nabla^{2} \rho_{\mathrm{cp}}\left(\mathrm{e} \AA^{-5}\right)\end{array}$} & \multicolumn{2}{|c|}{ Ellipticity } \\
\hline & & $\exp$ & theo & $\exp$ & theo & $\exp$ & theo \\
\hline \multicolumn{8}{|l|}{ IV } \\
\hline Mn1-O1 & $2.2009(3)$ & $0.33(1)$ & 0.30 & $5.87(14)$ & $4.87(5)$ & $0.2(2)$ & $0.37(4)$ \\
\hline $\mathrm{Mn} 1-\mathrm{O} 2^{i i}$ & $2.2027(3)$ & $0.36(1)$ & 0.31 & $6.11(25)$ & $5.15(3)$ & $0.3(3)$ & $0.41(3)$ \\
\hline $\mathrm{Mn} 1-\mathrm{O} 3^{i}$ & $2.1404(3)$ & $0.37(3)$ & 0.34 & $7.40(33)$ & $6.00(2)$ & $0.2(2)$ & $0.22(2)$ \\
\hline \multicolumn{8}{|l|}{$\mathbf{V}$} \\
\hline $\mathrm{Cu} 1-\mathrm{O} 1$ & $2.0008(7)$ & $0.50(1)$ & 0.35 & $9.69(20)$ & $7.28(7)$ & 0.01 & $0.01(1)$ \\
\hline $\mathrm{Cu} 1-\mathrm{O} 2$ & $1.9432(7)$ & $0.59(2)$ & 0.40 & $11.90(44)$ & $8.67(6)$ & $0.02(1)$ & $0.02(1)$ \\
\hline $\mathrm{Cu} 1-\mathrm{O} 5$ & $2.3747(8)$ & 0.21 & 0.14 & $3.30(8)$ & $2.55(2)$ & 0.01 & 0.00 \\
\hline
\end{tabular}



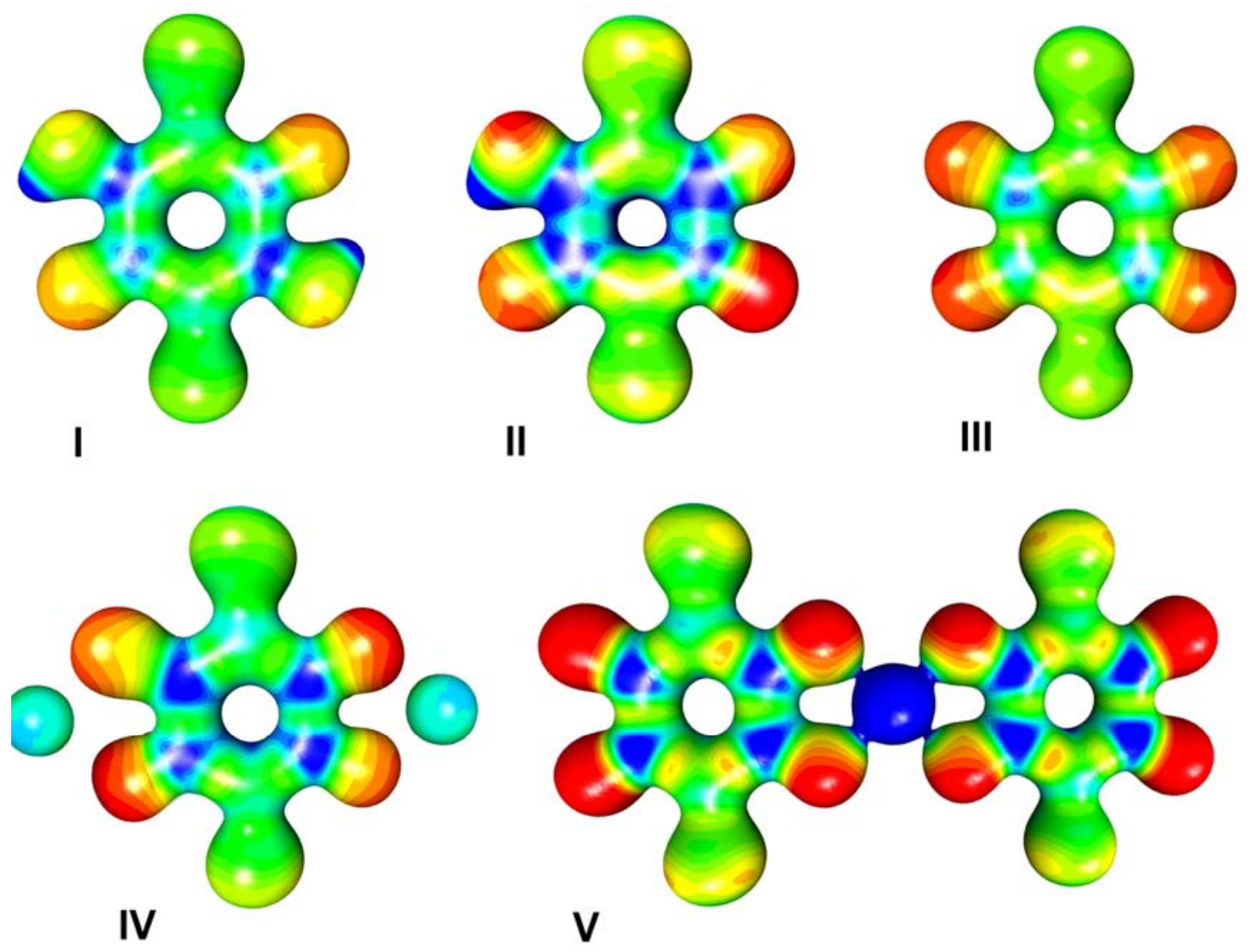

Figure 3 Multipolar experimental electrostatic potential mapped on electron density isosurface of 0.5 e $\AA^{-3}$ for neutral chloranilic acid (I), hydrogen chloranilate monoanion, (II), chloranilate dianion (III), chloranilate moiety acting as a bridging (bis)bidentate ligand (IV) and chloranilate moiety acting as a terminal bidentate ligand $(\mathbf{V})$. Colour scale: -0.1 (red) to +1 (dark blue) e $\AA^{-1}$. Apical water molecules in $\mathbf{I V}$ and $\mathbf{V}$ have been removed for clarity.

Neutral chloranilic acid: p-quinone (I)

As an example of the neutral acid, we selected the well-known chloranilic acid dihydrate, $\mathrm{H}_{2} \mathrm{CA} \cdot 2 \mathrm{H}_{2} \mathrm{O},{ }^{[49]}$ which is more stable and forms better crystals than its anhydrous analogue; ${ }^{[50]}$ so 
it is more suited for a charge density study. The molecule has a crystallographic symmetry $C_{i}$, and we will use atom numbering analogously to other structures (Fig. 1).

Since neutral quinones lack delocalisation of $\pi$ electrons, distribution of electron density and electrostatic potential in the ring is not uniformly distributed. ${ }^{[42]}$ The electrostatic potential map of neutral chloranilic (Fig. 3) reveals an expected excess of negative charge at the carbonyl oxygen atoms, and a slight excess of electron density at the double bonds, whereas the single ones are electron-poor. According to the topology of electron density (Tables 2 and S1), formally single bond $\mathrm{C} 2-\mathrm{C} 3$ (and its symmetry equivalent $\mathrm{C} 5-\mathrm{C} 6$ ) is stronger than $\mathrm{C} 1-\mathrm{C} 2$ (and its symmetry equivalent C4-C5): their respective bond orders are 0.94 and 0.89 . This is in accord with molecular geometry: bond C2-C3 is by $0.057 \AA$ shorter than C1-C2. Double bond C3-C4 (and its symmetry equivalent $\mathrm{C6}$ - $\mathrm{C} 1)$ is slightly longer than average $\mathrm{C}=\mathrm{C}$ bonds $(d=1.299-1.331 \AA),{ }^{[51]}$ with bond order of 1.54. The C-O bonds are more similar. The carbonyl bonds are slightly elongated with bond order 1.50 and have considerably lower $\rho_{\mathrm{cp}}$ electron density than formal double bonds. On the other hand, the hydroxyl C-O bonds are nearly $0.1 \AA$ shorter than typical single bonds (in hydroquinones they are typically 1.38-1.40 Å long) with bond order of 1.19. Accordingly, a weak electron delocalisation in the conjugated system O1-C1-C6-C5-O4 and its symmetry equivalent, O2-C2-C3-C4-O3 was observed. These two systems are separated by single C1-C2 bond. Chloranilic acid contains distinguishable formally single and double bonds as revealed by their geometrical parameters, electron density and IR bands. ${ }^{[37,40]}$ Thus, one can conclude that the neutral chloranilic acid has indeed a structure of $p$-quinone as shown in Scheme 1.

\section{Hydrogen chloranilate monoanion (II)}


A detailed charge-density study of potassium hydrogen chloranilate dihydrate, $\mathrm{KHCA} \cdot 2 \mathrm{H}_{2} \mathrm{O}$, has already been published ${ }^{[9]}$ and we only provide data for comparison to other structures.

Electrostatic potential is shown in Fig. 3. Topology of electron density reveals two different halves of the molecule: the protonated fragment (O1-C1-C6-C5-O4) shows similarity with one half of a neutral molecule, with distinguishable single and double bonds (Tables 1, 2, and S2). On the other hand, the deprotonated fragment (O2-C2-C3-C4-O3) has a fully delocalised system with all bond orders between 1.33 and 1.59 (average about 1.50, Tables 2 and S2). The negative charge is delocalised throughout the fragment O2-C2-C3-C4-O3 (Tables 3 and S7). The $\mathrm{C} 1-\mathrm{C} 2$ and symmetrically equivalent $\mathrm{C} 4-\mathrm{C} 5$ bonds are even weaker than in the neutral molecule since their orders are significantly lower than 1.

\section{Chloranilate dianion: two delocalised systems separated by two single bonds (III)}

Among several salts comprising chloranilate dianion tested, the best diffraction data were obtained from its potassium salt monohydrate, $\mathrm{K}_{2} \mathrm{CA} \cdot \mathrm{H}_{2} \mathrm{O} .{ }^{[1]}$

From electrostatic potential (Fig. 3) and topology of electron density (Tables 1, 2 and S3), it is evident that the chloranilate dianion comprises two fully delocalised $\pi$ systems (O1-C1-C6-C5-O4 and $\mathrm{O} 2-\mathrm{C} 2-\mathrm{C} 3-\mathrm{C} 4-\mathrm{O} 3$, respectively) joined by two single bonds (Fig. 2). The two units of negative charge are also delocalised on the two pairs of oxygen atoms (Tables 3 and S10). Since the dianion has a crystallographic symmetry $C_{i}$, its two $\pi$ systems are equivalent. It is interesting to note the descending electron density value and topological order of the single bonds $\mathrm{C} 1-\mathrm{C} 2$ and its symmetry equivalent C4-C5: They are strongest in the neutral molecule and the weakest in the dianion (bond orders of 0.89 and 0.76 , respectively). Additional charge of the anions or perhaps enhanced electron delocalisation apparently weakens these bonds. 


\section{Bridging (bis)bidentate ligand: dianion-like (IV)}

One of the simplest coordination polymers with bridging (bis)bidentate chloranilate ligand is $\left[\mathrm{Mn}(\mathrm{CA})\left(\mathrm{H}_{2} \mathrm{O}\right)\right]_{n} \cdot{ }^{[18]}$ It comprises a centrosymmetric chloranilate ligand with a dianion-like structure: ${ }^{[12,15]}$ two fully delocalised $\pi$ electron systems (O1-C1-C6-C5-O4 and symmetrically equivalent $\mathrm{O} 2-\mathrm{C} 2-\mathrm{C} 3-\mathrm{C} 4-\mathrm{O} 3)$ separated by two single $\mathrm{C}-\mathrm{C}$ bonds $(\mathrm{C} 1-\mathrm{C} 2$ and its symmetry equivalent C4-C5, with bond order of 0.90; Fig. 2). Four C-C bonds in the delocalised system are essentially equal, with orders of 1.53 and 1.56 , while the four C-O have an order of 1.29 (Tables 1,2 and S4). The values obtained are in accord with IR spectra revealing a single C-O stretching vibration, only. ${ }^{[12,15]}$

Compared to the uncoordinated dianion (III), C-O bonds are apparently weaker when in a complex (Tables 1 and 2), due to formation of coordination bonds, i.e. transfer of electron density from oxygen atoms towards the manganese centre. However, some electron density is transferred to $\mathrm{C}-\mathrm{C}$ bonds, which are considerably stronger than in III.

\section{Terminal bidentate ligand: o-quinone $(\mathbf{V})$}

To study chloranilate acting as a terminal bidentate ligand, the complex salt $\left[\mathrm{Cu}(\mathrm{CA})_{2}\left(\mathrm{H}_{2} \mathrm{O}\right)_{2}\right] \mathrm{Him}_{2}(\mathrm{Him}=$ imidazolium$)$, recently described by ${ }^{[15]},{ }^{[15}$ was chosen, which comprises a centrosymmetric dianion $\left[\mathrm{Cu}(\mathrm{CA})_{2}\left(\mathrm{H}_{2} \mathrm{O}\right)_{2}\right]^{2-}$. Molecular geometry (Table 1) and IR spectrum suggest an $o$-quinoid form of the chloranilate moiety, ${ }^{[15]}$ but charge density data indicate that a small degree of electron delocalisation is also present (Tables 2 and S5, Figure 2). "Pure" single bonds $\mathrm{C} 1-\mathrm{C} 2$ and $\mathrm{C} 4-\mathrm{C} 5$, which do not take part in delocalisation are severely electrondepleted and thus weakened (their bond orders are 0.64 and 0.55 , respectively). The other two 
formally single bonds (C3-C4 and C5-C6) are in fact considerably stronger than typical single CC bonds (respective bond orders of 1.18 and 1.17), while formally double bonds C2-C3 and C5C6 are weaker (respective bond orders of 1.37 and 1.46). Difference between C-O bonds is less pronounced: those facing the metal are closer to single bonds (respective bond orders of 1.30 and 1.27), while the uncoordinated ones are stronger (bond orders of 1.38). This implies a partial electron delocalisation in the $\mathrm{O} 1-\mathrm{C} 1-\mathrm{C} 6-\mathrm{C} 5-\mathrm{O} 4$ and $\mathrm{O} 2-\mathrm{C} 2-\mathrm{C} 3-\mathrm{C} 4-\mathrm{O} 3$ fragments. The electronic structure of the chloranilate acting as a terminal bidentate ligand thus shows a slight variation compared to an $o$-quinone structure.

\section{CONCLUSIONS}

We confirmed by X-ray charge density and AIM analysis the expected structures of the five species of chloranilic acid: neutral molecule, mono- and dianion, and two complexation chelating modes - bridging (bis)bidentate and terminal bidendate. The neutral chloranilic acid (I) has a $p$ quinoid structure with distinguishable single and double bonds and very little electron delocalisation. Its monoanion (II) has $\pi$ electrons delocalised over a half of the ring, while the other half has distinguishable single and double bonds. The dianion (III) has two delocalised fragments separated by two single bonds. The chloranilate moiety acting as a bridging (bis)bidentate ligand (IV) also has a dianion-like structure. Acting as a terminal bidentate ligand (V), it has an $o$-quinone-like structure with a slight degree of electron delocalisation; nevertheless, formally single and double bonds can be distinguished.

We have also quantitatively assessed the role of delocalisation of the negative charge and inductive effect of chlorine substituents in stabilisation of the anion. 
It is interesting to note that simple Lewis-style diagrams shown in Scheme 1 are in a good agreement with our structures obtained by AIM-analysis of experimental charge density. Therefore, the Lewis model of chemical bonding, over 100 years old, ${ }^{[1-54]}$ is still valid and useful. The sophisticated modern methods merely corroborated it.

\section{EXPERIMENTAL}

\section{Preparation}

Chloranilic acid dihydrate was prepared by the original Graebe method ${ }^{[2]}$ and recrystallised from an aqueous solution. Other compounds were prepared by known procedures. ${ }^{[1,7,15,18]}$

\section{$X$-ray diffraction and multipolar refinement}

For all crystals, highly redundant diffraction data were collected to the maximum resolution of $0.50 \AA$.

X-ray diffraction measurements of compounds I and III were performed at $110 \mathrm{~K}$ on an Oxford Diffraction SuperNova diffractometer equipped with a microfocus Mo tube and CCD detector. CrysAlis PRO program package ${ }^{[55]}$ was used for was used for data reduction and analytical absorption correction. The multiple integrated reflections were averaged for the appropriate space groups using SORTAV ${ }^{[56]}$ adapted to area detector data.

A single crystal of IV was measured at $100 \mathrm{~K}$ on an Oxford Rigaku XtaLab Synergy S diffractometer with a PhotonJet Mo source and HyPix pixel detector. CrysAlis PRO program package $^{[55]}$ was used for data reduction and absorption correction. The multiple integrated 
reflections were averaged for the appropriate space groups using SORTAV ${ }^{[56]}$ adapted to area detector data.

A single crystal of $\mathbf{V}$ was measured on a Bruker D8 Venture diffractometer at $100 \mathrm{~K}$. Program package Bruker Apex ${ }^{[57]}$ was used for data reduction and analytical absorption correction. The multiple integrated reflections were averaged for the appropriate space groups using SORTAV ${ }^{[56]}$ adapted to area detector data.

Spherical-atom models were refined using SHELXL-97; ${ }^{[58]}$ atomic coordinates were taken from the room-temperature structures. ${ }^{[1,15,18,49]}$

For multipolar refinement ( $v s . F^{2}$ ) the program package $M o P r o{ }^{[59]}$ was used. Chlorine, copper and manganese atoms were modelled up to hexadecapole level, $\mathrm{O}, \mathrm{N}$ and $\mathrm{C}$ as octupolar and hydrogen atoms with one dipole along $\mathrm{H}-\mathrm{X}$ bond directionr. Vibrations of chlorine, copper and manganese atoms were refined as anharmonic using third-order Gram-Charlier coefficients in IV and $\mathbf{V}$ and fourth-order Gram-Charlier coefficients in I and III. Anisotropic parameters for hydrogen atoms were calculated by the $S H A D E 3$ server ${ }^{[60]}$ and imported into the multipolar model (and constrained during the refinement); O-H distances were restrained to 0.967(2) $\AA$.

Topological bond orders were calculated using the formula ${ }^{[61]}$

$$
n_{\text {topo }}=a+b \lambda_{3}+c\left(\lambda_{1}+\lambda_{2}\right)+d \rho_{\mathrm{cp}}
$$

Coefficients $a, b, c$ and $d$ were taken from the literature: for C-C bonds $a=-0.522, b=-1.695$, $c=0.00, d=8.473 ;^{[62]}$ for $\mathrm{C}-\mathrm{O}$ bonds $a=-0.427, b=-0.240, c=0.280, d=6,464 ; ;^{[63]}$ for O-H bonds and $\mathrm{H} \cdots \mathrm{O}$ hydrogen bonds $a=0.00, b=-0.10, c=0.14, d=3.32 .{ }^{[64]}$ ESDs of the charge density properties were estimated by the recently published method. ${ }^{[65]}$

Geometry, charge-density and electrostatic properties calculations were performed by MoPro; ${ }^{[59]}$ molecular graphic were prepared using MoProViewer ${ }^{[66]}$ and ORTEP-3. ${ }^{[67]}$ 
Crystallographic and refinement data are shown in Table 5; additional details on refinement are deposited as Supporting Information.

\section{Quantum chemical calculations}

We performed quantum calculations using the CRYSTAL17 software for periodic DFT. ${ }^{[68]} \mathrm{We}$ utilised atomic coordinates after multipolar refinement with no further geometry optimisation. Compounds were modelled on the B3LYP/6-31G(d,p) theory level, using either the original Pople basis sets ${ }^{[69-71]}$ or basis sets modified for periodic DFT calculations when available. ${ }^{[72]}$ The only exception was the potassium atom, for which we used a modified $\mathrm{pVTZ}$ basis set ${ }^{[73]}$ since basis sets became linearly dependent when we introduced potassium 6-31G or 6-311G basis functions.

Once CRYSTAL17 calculated the wave function, we used the Properties program to obtain structure factors. We refined multipolar parameters (i.e. everything but the scale factor, coordinates and ADPs) against these structure factors in MoPro. ${ }^{[59]}$ We performed the same analyses on theoretical charge density for comparison with experimental results. Additionally, in order to obtain information on theoretical atomic charges in the studied compounds, we performed topological analysis of the periodic electron density adopting the QTAIM approach using the TOPOND14 program, ${ }^{[74]}$ integrated with CRYSTAL17. 
Table 5 Crystallographic, data collection and experimental charge-density refinement details.

\begin{tabular}{|c|c|c|c|c|}
\hline Compound & I & III & IV & $\mathbf{V}$ \\
\hline Empirical formula & $\mathrm{C}_{6} \mathrm{H}_{6} \mathrm{Cl}_{2} \mathrm{O}_{6}$ & $\mathrm{C}_{6} \mathrm{H}_{2} \mathrm{Cl}_{2} \mathrm{KO}_{5}$ & $\begin{array}{l}\mathrm{C}_{6} \mathrm{H}_{6} \mathrm{Cl}_{2} \mathrm{MnO} \\
7\end{array}$ & $\mathrm{C}_{9} \mathrm{H}_{7} \mathrm{Cl}_{2} \mathrm{Cu}_{0.5} \mathrm{~N}_{2} \mathrm{O}_{5}$ \\
\hline Formula wt. / $\mathrm{g} \mathrm{mol}^{-1}$ & 123.0 & 264.08 & 315.94 & 325.83 \\
\hline $\begin{array}{l}\text { Crystal dimensions } \\
\mathrm{mm}\end{array}$ & $\begin{array}{l}/ \quad 0.199 \times 0.141 \\
\times 0.073\end{array}$ & $\begin{array}{l}0.267 \times 0.166 \\
\times 0.131\end{array}$ & $\begin{array}{l}0.15 \times 0.08 \times \\
0.07\end{array}$ & $\begin{array}{llll}0.415 & \mathrm{x} & 0.052 \mathrm{x} \\
0.031 & & & \end{array}$ \\
\hline Space group & $P 2{ }_{1} / c$ & $C 2 / c$ & $C 2 / c$ & $P \overline{1}$ \\
\hline$a / \AA$ & $8.54236(12)$ & $16.0461(3)$ & $4.86973(5)$ & $8.1698(9)$ \\
\hline$b / \AA$ & $10.29026(16)$ & $4.77889(6)$ & $14.27534(16)$ & $8.6625(9)$ \\
\hline$c / \AA$ & $5.12411(7)$ & $16.6660(2)$ & $14.03079(13)$ & $9.15250(10)$ \\
\hline$\alpha / \circ$ & 90 & 90 & 90 & $69.681(4)$ \\
\hline$\beta /{ }^{\circ}$ & $104.3875(13)$ & $117.711(2)$ & $93.4823(9)$ & $70.769(4)$ \\
\hline$\gamma /{ }^{\circ}$ & 90 & 90 & 90 & $68.000(4)$ \\
\hline$V / \AA^{3}$ & $436.299(11)$ & $927.75(3)$ & $973.578(17)$ & $548.20(9)$ \\
\hline$Z$ & 2 & 4 & 4 & 2 \\
\hline$D_{\text {calc }} / \mathrm{g} \mathrm{cm}^{-3}$ & 1.866 & 2.171 & 2.149 & 1.975 \\
\hline$\mu / \mathrm{mm}^{-1}$ & 0.744 & 1.590 & 1.915 & 1.553 \\
\hline$\Theta$ range $/{ }^{\circ}$ & $3.07-65.36$ & $2.87-65.67$ & $4.07-45.26$ & $2.44-45.48$ \\
\hline$T / \mathrm{K}$ & $109.9(3)$ & $109.9(3)$ & $99.97(17)$ & $100(2)$ \\
\hline Radiation wavelength & $\begin{array}{l}0.71073 \\
(\mathrm{MoK} \alpha)\end{array}$ & $\begin{array}{l}0.71073 \\
(\operatorname{MoK} \alpha)\end{array}$ & $\begin{array}{l}0.71073 \\
(\mathrm{MoK} \alpha)\end{array}$ & $0.71073(\mathrm{MoK} \alpha)$ \\
\hline Diffractometer type & SuperNova & SuperNova & $\begin{array}{l}\text { XtaLab } \\
\text { Synergy S }\end{array}$ & Bruker D8 Venture \\
\hline \multirow[t]{3}{*}{ Range of $h, k, l$} & $-21<h<21$ & $-16<h<15$ & $-9<h<9$ & $-16<h<16$ \\
\hline & $-26<k<25$ & $-17<k<17$ & $-28<k<27$ & $-17<k<17$ \\
\hline & $-13<l<13$ & $-22<l<22$ & $-27<l<28$ & $-18<l<18$ \\
\hline Reflections collected & 110581 & 155428 & 26111 & 97076 \\
\hline
\end{tabular}




$\begin{array}{lllll}\text { Independent reflections } & 7884 & 8088 & 4082 & 9220 \\ \text { Observed reflections } & 6385 & 6907 & 3858 & 7513 \\ (I \geq 2 \sigma) & & & & \\ \text { Absorption correction } & \text { analytical } & \text { analytical } & \text { multi-scan } & \text { analytical } \\ T_{\min }, T_{\max } & 0.539 ; 1.000 & 0.673 ; 1.000 & 0.85918 ; & 0.725,0.972 \\ & & & 1.00000 & \\ R_{\text {int }} & 0.064 & 0.038 & 0.0132 & 0.0397\end{array}$

\section{Spherical refinement}

Weighting scheme: $a$

$$
0.040
$$

0.027

0.0241

0.0344

$b \quad(*)$

0.047

0.184

0.2357

0.0577

$R(F)(I>2 \sigma(I))$

0.0357

0.0229

0.0181

0.0292

$R_{w}\left(F^{2}\right)(I>2 \sigma(I))$

0.1339

0.1025

0.0424

0.0676

Goodness of fit

1.078

1.076

1.028

1.031

$\mathrm{H}$ atom treatment

riding

riding

riding

riding

No. of parameters

69

74

98

223

No. of restraints

0

0

0

0

$\Delta \rho_{\max ,} \Delta \rho_{\min }\left(\mathrm{e} \AA^{-3}\right)$

0.748; -0.704; 0.083

$0.748 ;-0.671$
0.094

$0.721 ;-0.249 ; \quad 0.813$; 0.093

-0.936 ;

$\Delta \rho_{\mathrm{rms}}\left(\mathrm{e} \AA^{-3}\right)$

\section{Multipolar refinement}

\begin{tabular}{|c|c|c|c|c|}
\hline Weighting scheme $\mathrm{w}^{*}$ & $\begin{array}{l}w \\
=1 /\left[1.24 * \backslash s^{2}(\right. \\
\left.\left.F_{\mathrm{o}}^{2}\right)\right]\end{array}$ & $\begin{array}{l}w \\
=1 /\left[0.98 * \backslash s^{2}(\right. \\
\left.\left.F_{\mathrm{o}}^{2}\right)\right]\end{array}$ & $\begin{array}{l}w \\
=1 /\left[1.20 * \backslash s^{2}(\right. \\
\left.\left.F_{\mathrm{o}}^{2}\right)\right]\end{array}$ & $\begin{array}{l}w \\
=1 /\left[0.497 * \backslash s^{2}\left(F_{\mathrm{o}}^{2}\right)\right]\end{array}$ \\
\hline$R(F)(I>2 \sigma(I))$ & 0.0267 & 0.0236 & 0.0099 & 0.0194 \\
\hline$R_{w}\left(F^{2}\right)(I>2 \sigma(I))$ & 0.0458 & 0.0363 & 0.0147 & 0.0427 \\
\hline Goodness of fit & 0.967 & 1.004 & 0.957 & 1.009 \\
\hline
\end{tabular}




\begin{tabular}{|c|c|c|c|c|c|}
\hline $\mathrm{H}$ atom treatment & $\begin{array}{l}\text { restrained, } \\
\text { anisotropic } \\
\left(\mathrm{H}_{2} \mathrm{CA}\right) \quad \& \\
\text { isotropic } \\
\left(\mathrm{H}_{2} \mathrm{O}\right)\end{array}$ & $\begin{array}{l}\text { restrained, } \\
\text { isotropic }\end{array}$ & $\begin{array}{l}\text { restrained, } \\
\text { isotropic }\end{array}$ & $\begin{array}{l}\text { restrained, } \\
\text { anisotropic }\end{array}$ & \\
\hline No. of parameters & 233 & 255 & 57 & 413 & \\
\hline No. of restraints & 82 & 76 & 3 & 62 & \\
\hline $\begin{array}{l}\Delta \rho_{\max }, \Delta \rho \min , \Delta \rho_{\text {rms }}\left(\mathrm{e} \AA^{-}\right. \\
\left.{ }^{3}\right)\end{array}$ & $\begin{array}{l}0.409 ;-0.323 ; \\
0.055\end{array}$ & $\begin{array}{l}0.496 ;-0.475 \\
0.098\end{array}$ & $\begin{array}{l}0.279 ;-0.277 \\
0.043\end{array}$ & $\begin{array}{l}0.475 \\
0.075\end{array}$ & -0.559 \\
\hline
\end{tabular}

\section{ASSOCIATED CONTENT}

Supporting Information. Experimental details (residual densities, XDRK plots), ORTEP drawings and details on experimental electron density (deformation density, Laplacians, details on the cation from compound $\mathbf{V}$ ), detailed tables with topology of electron density and atomic charges (experimental and theoretical).

\section{AUTHOR INFORMATION}

\section{Corresponding Author}

KM: Department of Physical Chemistry, Rudjer Bošković Institute, Bijenička 54, HR-10000 Zagreb, Croatia, e-mail: kmolcano@irb.hr ; CJ: Cristallographie, Résonance Magnetique et Modélisations, UMR 7036, Institut Jean Barriol, CNRS and Université de Lorraine BP 70239, F54506 Vandoeuvre-les-Nancy CEDEX, France, e-mail: christian.jelsch@univ-lorraine.fr.

\section{Author Contributions}

The manuscript was written through contributions of all authors. 


\section{Funding Sources}

The financing from the Croatian Science Foundation (grant no. IP-2014-09-4079) and Ministry of Science, Education and Sports of the Republic of Croatia (French-Croatian bilateral - Hubert Curien grant for years 2015-2016 and 2017-2018) is gratefully acknowledged. This research was supported in part by PL-Grid Infrastructure.

\section{ACKNOWLEDGMENT}

The authors thank the X-ray diffraction measurement facility of the Institut Jean Barriol, Université de Lorraine, France and Dr. Fraser White from Rigaku Oxford Diffraction Ltd. for data collection of a crystal of compound IV.

\section{ABBREVIATIONS}

$\mathrm{H}_{2} \mathrm{CA}$, neutral chloranilic acid; $\mathrm{HCA}$, hydrogen chloranilate monoanion; $\mathrm{CA}$, chloranilate dianion; Him, imidazolium cation; AIM, atoms-in-molecules.

\section{REFERENCES}

[1] Molčanov, K.; Kojić-Prodić, B.; Meden, A. Unique electronic and structural properties of 1,4-benzoquinones: crystallochemistry of alkali chloranilate hydrates, Croat. Chem. Acta, 2009, 82, 387-396.

[2] Graebe, C. Ueber Chloranil, Ann. Chem., 1891, 263, 16-31.

[3] Wallenfels, K.; Friedrich, K. Über Fluorchinone, II. Zur Hydrolyse und Alkoholyse des Fluoranils, Chem. Ber., 1960, 93, 3070-3082. 
[4] Kabir, M. K.; Miyazaki, N.; Kawata, S.; Adachi, K.; Kumagai, H.; Inoue, K.; Kitagawa, S.; Ijima, K.; Katada, M. Novel Intercalation Structures Constructed From Iron-Chloranilate Compounds, Coord. Chem. Rev., 2000, 198, 157-169.

[5] Kitagawa, S. Kawata, S. New Dimensions of Coordination Compounds of Oxocarbon Ligands. Structures and Properties, Coord. Chem. Rev., 2002, 224, 11-34.

[6] Molčanov, K.; Kojić-Prodić, B. Salts and cocrystals of chloranilic acid with organic bases; is it possible to predict a salt formation?, CrystEngComm, 2010, 12, 952-939.

[7] Molčanov, K.; Meden, A. \& Kojić-Prodić, B. $\pi$-Stacking of quinoid rings in crystals of alkali diaqua hydrogen chloranilates, CrystEngComm, 2009, 11, 1407-1415.

[8] Molčanov, K.; Sabljić, I. \& Kojić-Prodić, B. Face-to-face $\pi$-stacking in the multicomponent crystals of chloranilic acid, alkali hydrogenchloranilates, and water, CrystEngComm, 2011, 13, 4211-4217.

[9] Molčanov, K.; Stare, J.; Kojić-Prodić, B.; Lecomte, C.; Dahaoui, S.; Jelsch, C.; Wenger, E.; Šantić, A. \& Zarychta, B. A polar/ $\pi$ model of interactions explains face-to-face stacked quinoid rings: a case study in the crystal of potassium hydrogen chloranilate dihydrate, CrystEngComm, 2015, 17, 8645-8656.

[10] Molčanov, K.; Jurić, M.; Kojić-Prodić, B. A novel type of coordination mode of chloranilic acid leading to the formation of polymeric coordination ribbon in the series of mixed-ligand copper(II) complexes with 1,10-phenanthroline, Dalton Trans., 2014, 43, 7208-7218. 
[11] Molčanov, K.; Jurić, M.; Kojić-Prodić, B. Stacking of metal chelating rings with $\pi$-systems in mononuclear complexes of copper(II) with 3,6-dichloro-2,5-dihydroxy-1,4-benzoquinone (chloranilic acid) and 2,2'-bipyridine ligands, Dalton Trans., 2013, 42, 15756-15765.

[12] Androš Dubraja, L.; Molčanov, K.; Žilić, D.; Wenger, E.; Kojić-Prodić, B. Multifunctionality and size of the chloranilate ligand define the topology of transition metal coordination polymers, New J. Chem., 2017, 41, 6785-6794.

[13] Chatterjee, B. P.; Bhattacharya, K.; Kundu, N.; Choi, K.-I.; Clérac, R.; Chaudhury, M. Vanadium-Induced Nucleophilic IPSO Substitutions in a Coordinated Tetrachlorosemiquinone Ring: Formation of the Chloranilate Anion as a Bridging Ligand, Inorg. Chem., 2009, 48, 804806.

[14] Atzori, M.; Pop, F.; Auban-Senzier, P.; Gómez-García, C. J.; Canadell, E.; Artizzu, F.; Serpe, A.; Deplano, P.; Avarvari, N.; Mercuri, M. L. Structural Diversity and Physical Properties of Paramagnetic Molecular Conductors Based on Bis(ethylenedithio)tetrathiafulvalene (BEDTTTF) and the Tris(chloranilato)ferrate(III) Complex, Inorg. Chem., 2014, 53, 7028-7039.

[15] Jurić, M.; Molčanov, K.; Žilić, D.; Kojić-Prodić, B. From mononuclear to linear onedimensional coordination species of copper(II)-chloranilate: design and characterization, $R S C$ Adv., 2016, 6, 62785-62796.

[16] Kawata, S.; Kitagawa, S.; Kondo, M.; Furuchi I.; Munakata, M. Two-Dimensional Sheets of Tetragonal Copper(II) Lattices: X-Ray Crystal Structure and Magnetic Properties of $\left[\mathrm{Cu}\left(\mathrm{C}_{6} \mathrm{O}_{4} \mathrm{Cl}_{2}\right)\left(\mathrm{C}_{4} \mathrm{H}_{4} \mathrm{~N}_{2}\right)\right]$ n, Angew. Chem., Int. Ed., 1994, 33, 1759-1761. 
[17] Kawata, S.; Kitagawa, S.; Kondo, M.; Katada, M. Fabrication of infinite two- and threedimensional copper coordination polymers of chloranilic acid and its derivatives. Crystal structures and magnetic properties, Synth. Met., 1995, 71, 1917-1918.

[18] Kawata, S.; Kitagawa, S.; Kumagai, S.; Ishiyama, T.; Honda, K.; Tobita, H.; Adachi, K.; Katada, M. Novel Intercalation Host System Based on Transition Metal $\left(\mathrm{Fe}^{2+}, \mathrm{Co}^{2+}\right.$, $\left.\mathrm{Mn}^{2+}\right)$-Chloranilate Coordination Polymers. Single Crystal Structures and Properties, Chem. Mater., 1998, 10, 3902-3912.

[19] Robl, C. Komplexe mit substituierten 2,5-Dihydroxy-p-benzochinonen: $\mathrm{EA}\left[\mathrm{C}_{6}\left(\mathrm{NO}_{2}\right)_{2} \mathrm{O}_{4}\right] \cdot 4 \mathrm{H}_{2} 0(\mathrm{EA}=\mathrm{Ca}, \mathrm{Sr})$. Z. Naturforsch. $B, \mathbf{1 9 8 7}, 42 b, 972-976$.

[20] Decurtins, S.; Schmalle, H. W.; Zhen, L.-M.; Ensling, J. A new polymeric compound containing copper(II)-chloranilate chains: synthesis, crystal structure and magnetic properties of $[\mathrm{Cu}(\mathrm{DCMB})(\mathrm{CA})]_{n}\left(\mathrm{DCMB}=3,3^{\prime}\right.$-dicarbomethoxy-2,2'-bipyridyl; $\mathrm{CA}=$ dianion of 3,6-dichloro2,5-dihydroxy- 1,4-benzoquinone). Inorg. Chim. Acta, 1996, 244, 165-170.

[21] Abrahams, B. F.; Lu, K. B.; Moubaraki, B.; Murray, K. S.; Robson, R. X-Ray diffraction and magnetic studies on a series of isostructural divalent metal chloranilates with zigzag polymeric chain structures and on a dinuclear iron(III) chloranilate, J. Chem. Soc., Dalton Trans., 2000, 1793-1797.

[22] Abrahams, B. F.; Grannas, M. J.; Hudson, T. A.; Hughes, S. A.; Pranoto, N. H.; Robson, R. Synthesis, structure and host-guest properties of $\left(\mathrm{Et}_{4} \mathrm{~N}\right)_{2}\left[\mathrm{Sn}^{\mathrm{IV}} \mathrm{Ca}{ }^{\mathrm{II}}(\text { chloranilate })_{4}\right]$, a new type of robust microporous coordination polymer with a 2D square grid structure, Dalton Trans., 2011, $40,12242-12247$. 
[23] Kabir, M. K.; Kawahara, M.; Kumagai, H.; Adachi, K.; Kawata, S.; Ishii, T.; Kitagawa, S. The rational syntheses of manganese-chloranilate compounds: crystal structures and magnetic properties, Polyhedron, 2001, 20, 1417-1422.

[24] Atzori, M.; Benmansour, S.; Minguez-Espallargas, G.; Clemente-Léon, M.; Abhervé, A.; Gómez-Claramunt, P.; Coronado, E.; Artizzu,F.; Sessini, E.; Deplano, P.; Serpe, A.; Mercuri, M. L.; Gómez-García, C. J. A Family of Layered Chiral Porous Magnets Exhibiting Tunable Ordering Temperatures, Inorg. Chem., 2013, 52, 10031-10040.

[25] Benmansour, S.; Vallés-García, C.; Gómez-Claramunt, P.; Mínguez Espallargas, G.; Gómez-García, C. J. 2D and 3D Anilato-Based Heterometallic M(I)M(III) Lattices: The Missing Link, Inorg. Chem., 2015, 54, 5410-5418.

[26] Atzori, M; Pop, F.; Auban-Senzier, P.; Clérac, R.; Canadell, E.; Mercuri, M. L.; Avarvari, N. Complete Series of Chiral Paramagnetic Molecular Conductors Based on Tetramethylbis(ethylenedithio)-tetrathiafulvalene (TM-BEDT-TTF) and Chloranilate-Bridged Heterobimetallic Honeycomb Layers, Inorg. Chem., 2015, 54, 3643-3653.

[27] Kumagai, H.; Kawata, S.; Kitagawa, S. Fabrication of infinite two-dimensional sheets of tetragonal metal(II) lattices: X-ray crystal structures and magnetic properties of $[\mathrm{M}(\mathrm{CA})(\mathrm{pyz})]_{n}$ $\left(\mathrm{M}^{2+}=\mathrm{Mn}^{2+}\right.$ and $\mathrm{Co}^{2+} ; \mathrm{H}_{2} \mathrm{CA}=$ chloranilic acid; pyz=pyrazine), Inorg. Chim. Acta, 2002, 337, 387392.

[28] Abrahams, B. F.; Coleiro, J.; Hoskins, B. F.; Robson, R. Gas hydrate-like pentagonal dodecahedral $\mathrm{M}_{2}\left(\mathrm{H}_{2} \mathrm{O}\right)_{18}$ cages $(\mathrm{M}=$ lanthanide or $\mathrm{Y})$ in 2,5-dihydroxybenzoquinone-derived coordination polymers, Chem. Commun, 1996, 603-604. 
[29] Abrahams, B. F.; Coleiro, J.; Ha, K.; Hoskins, B. F.; Orchard, S. D.; Robson, R. Dihydroxybenzoquinone and chloranilic acid derivatives of rare earth metals, J. Chem. Soc., Dalton Trans., 2002, 1586-1594.

[30] Benmansour, S.; Vallés-García, C.; Gómez-García, C. J. A H-bonded Chloranilate Chain with an Unprecedented Topology, Struct. Chem. \& Crystallogr. Commun., 2015, 1, 1-7.

[31] Abhervé, A.; Clemente-Léon, M.; Coronado, E.; Gómez-García, C. J.; Verneret, M. OneDimensional and Two-Dimensional Anilate-Based Magnets with Inserted Spin-Crossover Complexes, Inorg. Chem., 2014, 53, 12014-12026.

[32] Abhervé, A.; Mañas-Valero, S.; Clemente-Léon, M.; Coronado, E. Graphene related magnetic materials: micromechanical exfoliation of 2D layered magnets based on bimetallic anilate complexes with inserted $\left[\mathrm{Fe}^{\mathrm{III}}\left(\mathrm{acac}_{2}-\text { trien }\right)\right]^{+}$and $\left[\mathrm{Fe}^{\mathrm{III}}\left(\mathrm{sal}_{2} \text {-trien }\right)\right]^{+}$molecules, Chem. Sci., 2015, 6, 4665-4673.

[33] Mercuri, M. L.; Congiu, F.; Concas, G.; Sahadevan, S. A. Recent Advances on AnilatoBased Molecular Materials with Magnetic and/or Conducting Properties, Magnetochemistry, $\mathbf{2 0 1 7}, 3,17$.

[34] Mallegowda, S. M.; Deepakumari, H. N.; Revanasiddappa, H. D. Spectrophotometric Determination of Valsartan using p-Chloranilic Acid as $\pi$-Acceptor in Pure and in Dosage Forms, J. Appl. Pharm. Sci. 2013, 3, 113-116.

[35] Saliba-Silva, A. M.; dos Santos, O.; de Carvalho, F. U.; Riella, H. G.; Durazzo, M. Determination of Uranium Traces in Nuclear Reactor IEA-R1 Pool Water, World J. Nucl. Sci. Techn. 2017, 7, 155-166. 
[36] Grabarczyk, M.; Adamczyk, M. Bismuth film electrode and chloranilic acid as a new alternative for simple, fast and sensitive Ge(IV) quantification by adsorptive stripping voltammetry, $R S C A d v$. 2018, $8,15215-15221$.

[37] Biliškov, N.; Kojić-Prodić, B.; Mali, G.; Molčanov, K.; Stare, J. A partial proton transfer in hydrogen bond $\mathrm{O}-\mathrm{H} \cdots \mathrm{O}$ in crystals of anhydrous potassium and rubidium complex chloranilates, J. Phys. Chem. A, 2011, 115, 3154-3166.

[38] Molčanov, K.; Kojić-Prodić, B. Face-to-face stacking of quinoid rings of alkali salts of bromanilic acid, Acta Cryst. B, 2012, 68, 57-65.

[39] Molčanov, K.; Kojić-Prodić, B.; Babić, D.; Stare, J. Face-to-face stacking of dianionic quinoid rings in crystals of alkali salts of 2,5-dihydroxyquinone in view of $\pi$-system polarization, CrystEngComm, 2013, 15, 135-143.

[40] Pawlukojć, A.; Bator, G.; Sobczyk, L.; Grech, E.; Nowicka-Scheibe, J. Inelastic neutron scattering, Raman, infrared and DFT theoretical studies on chloranilic acid, J. Phys. Org. Chem., 2003, 16, 709-714.

[41] Sovago, I.; Thomas, L. H.; Adam, M. S.; Capelli, S. C.; Wilson, C. C.; Farrugia, L. J. High resolution X-ray and neutron diffraction studies on molecular complexes of chloranilic acid and lutidines, CrystEngComm, 2016, 18, 5697-5709.

[42] Molčanov, K.; Jelsch, C; Landeros-Rivera, B.; Hernández-Trujillo, J.; Wenger, E.; Stilinović, V.; Kojić-Prodić, B.; Escudero-Adán, E. Partially covalent two-electron/multicentric bonding between semiquinone radicals, Cryst. Growth Des. 2019, 19, 391-402. 
[43] Molčanov, K.; Mou, Z.; Kertesz, M.; Kojić-Prodić, B.; Stalke, D.; Demeshko, S.; Šantić, A.; Stilinović, V. Two-electron / multicentre - pancake bonding in $\pi$-stacked trimers in a salt of tetrachloroquinone anion, Chem. Eur. J., 2018, 24, 8292-8297.

[44] Poulsen, R. D.; Bentien, A.; Graber, T.; Iversen, B. B Synchrotron charge-density studies in materials chemistry: $16 \mathrm{~K} \mathrm{X-ray} \mathrm{charge} \mathrm{density} \mathrm{of} \mathrm{a} \mathrm{new} \mathrm{magnetic} \mathrm{metal-organic} \mathrm{framework}$ material, $\left[\mathrm{Mn}_{2}\left(\mathrm{C}_{8} \mathrm{H}_{4} \mathrm{O}_{4}\right)_{2}\left(\mathrm{C}_{3} \mathrm{H}_{7} \mathrm{NO}\right)_{2}\right]$, Acta Crystallogr. A, 2004, A60, 382-389.

[45] Pillet, S.; Souhassou, M.; Mathonière, C.; Lecomte, C. Electron Density Distribution of an Oxamato Bridged $\mathrm{Mn}(\mathrm{II})-\mathrm{Cu}(\mathrm{II})$ Bimetallic Chain and Correlation to Magnetic Properties, $J$. Am. Chem. Soc., 2004, 126, 1219-1228.

[46] Wang, Y. Charge Density Analysis and Bond Characterization of 3d-Transition Metal Complexes, J. Chin. Chem. Soc., 2014, 61, 27-38.

[47] Gajda, R.; Wożniak, K. Charge density studies of an inorganic-organic hybrid pphenylenediammonium tetrachlorocuprate, Struct. Chem., 2017, 28, 1607-1622.

[48] Chuang, Y.-C.; Sheu, C.-F.; Lee, G.-H.; Chen, Y.-S.; Wang, Y. Charge density studies of $3 \underline{d}$ metal $(\mathrm{Ni} / \mathrm{Cu})$ complexes with a non-innocent ligand, Acta Crystallogr. B, 2017, B73, 634-642.

[49] Krogh Andersen, E. The crystal and molecular structure of hydroxyquinones and salts of hydroxyquinones. II. Chloranilic acid dihydrate, Acta Cryst. 1967, 22, 191-196.

[50] Krogh Andersen, E. The crystal and molecular structure of hydroxyquinones and salts of hydroxyquinones. I. Chloranilic acid, Acta Cryst. 1967, 22, 188-191. 
[51] Allen, F. H., Kennard, O., Watson, D. G., Brammer, L., Orpen, A. G. \& Taylor, R. International Tables for X-ray Crystallography, Volume C, 1st Edition, IUCr, 1992.

[52] Mingos, M. D. P. The Chemical Bond: Lewis and Kossel's Landmark Contribution, in Struct. Bond., The Chemical Bond - 100 Years Old and Getting Stronger I, 2016, 1-56.

[53] Stalke, D. Charge Density and Chemical Bonding, in Struct. Bond., The Chemical Bond 100 Years Old and Getting Stronger I, 2016, 57-88.

[54] Kit Sheong, F.; Chen, J.-W.; Lin, Z. Lewis Description of Bonding in Transition Metal Complexes, in Struct. Bond., The Chemical Bond - 100 Years Old and Getting Stronger I, 2016, 89-130.

[55] CrysAlis ${ }^{\text {Pro }}$, Rigaku Oxford Diffraction, 2017, version: 1.171.39.13a, Rigaku Corporation, Oxford, UK.

[56] Blessing, R. H. Data Reduction and Error Analysis for Accurate Single Crystal Diffraction Intensities, Crystallogr. Rev., 1987, 1, 3-58.

[57] APEX2, SADABS and SAINT. Bruker AXS Inc., Madison, Wisconsin, USA, 2010.

[58] Sheldrick, G. M. Crystal structure refinement with SHELXL, Acta Crystallogr. 2015, C71, 3-8.

[59] Jelsch, C.; Guillot, B.; Lagoutte A.; Lecomte, C. Advances in protein and small-molecule charge-density refinement methods using MoPro, J. Appl. Cryst., 2005, 38, 38-54.

[60] Madsen, A. Ø. SHADE web server for estimation of hydrogen anisotropic displacement parameters, J. Appl. Cryst., 2006, 39, 757-758. 
[61] Zarychta, B.; Zaleski, Z.; Kyzioł, J.; Dazskiewicz, Z.; Jelsch, C. Charge-density analysis of 1-nitroindoline: refinement quality using free $R$ factors and restraints, Acta Cryst. B, 2011, B67, $250-262$.

[62] Howard, S. T.; Lamarche, O. Description of covalent bond orders using the charge density topology, J. Phys. Org. Chem., 2003, 16, 133-141.

[63] Tsirelson, V. G.; Bartashevich, E. V.; Stash, A. I.; Potemkin, V. A. Determination of covalent bond orders and atomic valence indices using topological features of the experimental electron density, Acta Crystallogr. B, 2007, B63, 142-150.

[64] Bartashevich, E. V.; Nikulov, D. K.; Vener, M. V.; Tsirelson, V. G. QTAIMC study of the $\mathrm{X}-\mathrm{H} / \mathrm{H} \cdots \mathrm{O}$ bond order indices $(\mathrm{X}=\mathrm{O}, \mathrm{N}, \mathrm{C})$ in molecular systems, Comp. Theor. Chem., 2011, 973, 33-39.

[65] Fournier, B.; Guillot, B.; Lecomte, C.; Escudero-Adán,E.; Jelsch, C. A method to estimate statistical errors of properties derived from charge-density modelling, Acta Cryst. A, 2018, A74, $170-183$.

[66] Guillot, B. MoProViewer: a molecule viewer for the MoPro charge-density analysis program, Acta Cryst A., 2012, A68, s204.

[67] Farrugia, L. J. ORTEP-3 for Windows - a version of ORTEP-III with a Graphical User Interface (GUI), J. Appl. Cryst., 1997, 30, 565.

[68] Dovesi, R.; Orlando, R.; Erba, A.; Zicovich-Wilson, C. M.; Civalleri, B.; Casassa, S.; Maschio, L.; Ferrabone, M.; De La Pierre, M.; D’Arco P. CRYSTAL14: A program for the $a b$ initio investigation of crystalline solids, Int. J. Quantum Chem. 2014, 114 1287-1317. 
[69] Hariharan P. C.; Pople J. A. The influence of polarization functions on molecular orbital hydrogenation energies, Theor. Chim. Acta, 1973, 28, 213-222.

[70] Francl, M. M.; Pietro, W. J.; Hehre, W. J.; Binkley, J. S.; Gordon, M. S.; DeFrees, D. J.; Pople, J. A. Self-consistent molecular orbital methods. XXIII. A polarization-type basis set for second-row elements, J. Chem. Phys. 1982, 77, 3654-3666.

[71] EMSL Basis Set Exchange. 6-31+G* Basis Set: Lithium. https://bse.onl.gov/ bse/portal/user/anon/panel/Main/template/courier_content/js_peid/11543880926284. (last access 2018-05-22).

[72] Heyd, J.; Peralta, J. E.; Scuseria G. E.; Martin, R. L. Energy band gaps and lattice parameters evaluated with the Heyd-Scuseria-Ernzerhof screened hybrid functional, J. Chem. Phys. 2005, 123, 174101.

[73] Peintinger, M. F.; Oliveira D. V.; Bredow, T. Consistent Gaussian basis sets of triple-zeta valence with polarization quality for solid-state calculations, J. Comput. Chem., 2012, 34, 451459.

[74] Gatti C., Casassa S. TOPOND14 User’s Manual, September 12, 2017. 
TOC graphic

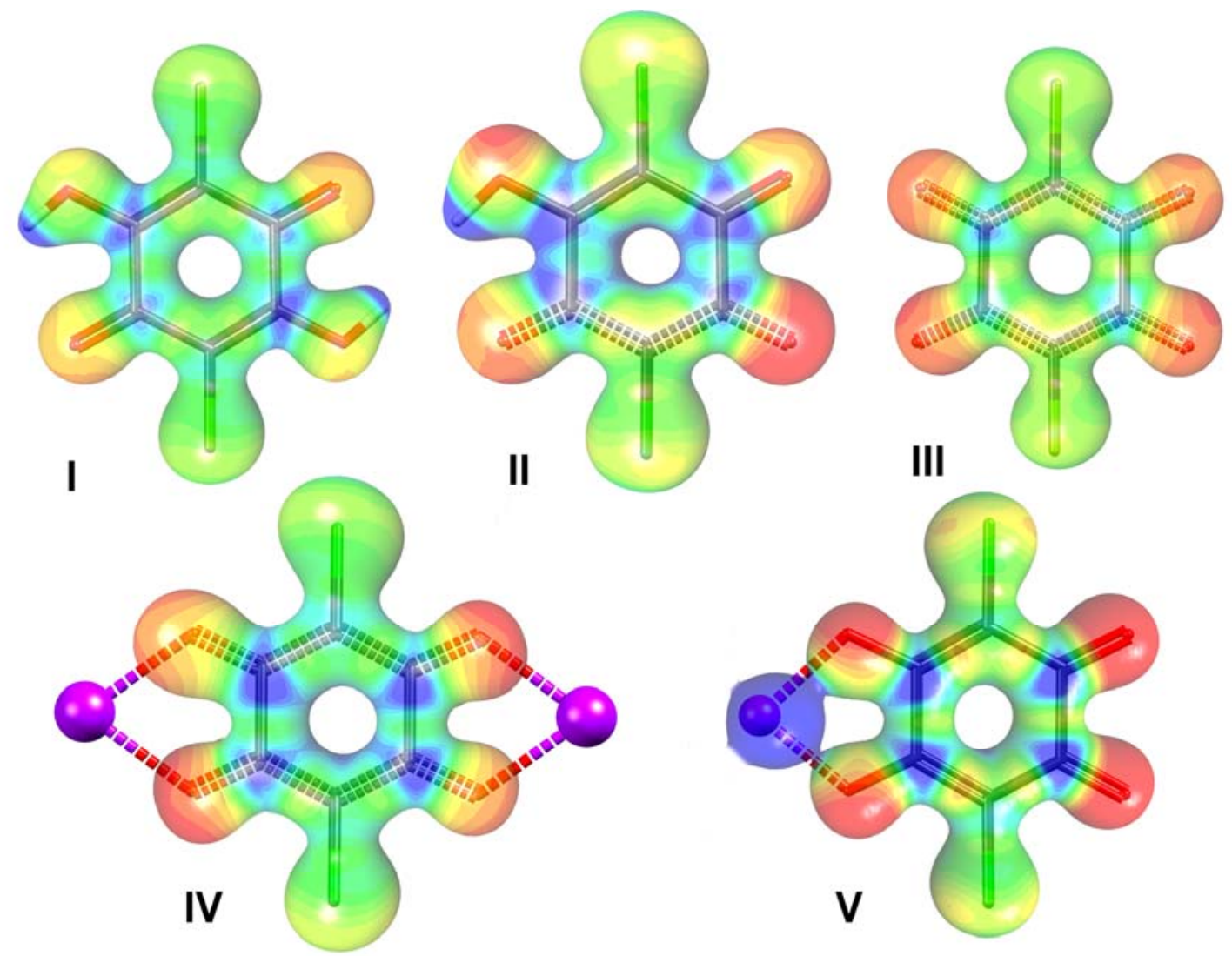

